\title{
O CINEMA E O AUDIOVISUAL COMO INSTRUMENTOS ÉTICOS DE DIFUSÃO DOS DIREITOS HUMANOS
}

\section{CINEMA AND AUDIOVISUAL AS ETHICAL INSTRUMENTS FOR THE DISSEMINATION OF HUMAN RIGHTS}

\author{
Leandra Duarte Silva Paiva*
}

\begin{abstract}
Resumo
O objetivo da pesquisa em questão é analisar o comportamento da produção audiovisual e cinematográfica ao longo do tempo, em seus principais e difusos meios de comunicação, frente à propagação dos direitos humanos e fundamentais e à aplicabilidade de temáticas como a ética, a cultura e a educação. Através do estudo da inserção do cinema no contexto da indústria cultural - situadas sob a perspectiva crítica de Adorno e Horkheimer -, das possibilidades de reinvenção advindas dos movimentos de ruptura com as formas padronizadas de fazer cinema e da observação de histórias desenvolvidas na contemporaneidade que viabilizam a emersão de pautas humanistas, o presente artigo busca apresentar narrativas comprometidas com pressupostos éticos nas produções audiovisuais e cinematográficas. Além disso, este trabalho busca apontar as travessias que tais criações podem percorrer diante da responsabilidade de exibir conteúdos engajados na dissipação de preconceitos, na formação de cidadãos e na construção de uma sociedade mais justa e igualitária.
\end{abstract}

Palavras-chave: Cinema. Audiovisual. Direitos Humanos. Ética.

\begin{abstract}
The objective of this research is to analyze the behavior of audiovisual and cinematographic production over time, in its main and diffuse means of communication, in view of the spread of human and fundamental rights and the applicability of themes such as ethics, culture and education. Through the study of the insertion of cinema in the context of the cultural industry - located under the critical perspective of Adorno and Horkheimer - , of the possibilities of reinvention arising from movements of rupture with the standardized ways of making cinema and the observation of stories developed in contemporary times that enable the emergence of humanist guidelines, this article seeks to present narratives committed to ethical assumptions in audiovisual and cinematographic productions. In addition,
\end{abstract}

Artigo submetido em 05 de junho de 2020 e aprovado em 13 de setembro de 2020.

* Graduanda em Direito pela Faculdade Mineira de Direito da PUC Minas. Atualmente, atua como pesquisadora na área de Direito Internacional, tendo sido integrante do Grupo de Estudos em Direito e Literatura. Possui interesse nas intersecções e atravessamentos do Direito com a Arte. E-Mail: leduartesgs@gmail.com 
this work seeks to point out the crossings that such creations can go through in the face of the responsibility of displaying contents engaged in the dissipation of prejudices, in the formation of citizens and in the construction of a more just and egalitarian society.

Keywords: Cinema. Audiovisual. Human Rights. Ethics.

\section{INTRODUÇÃO}

Este artigo tem como pressuposto principal a análise da trajetória das produções audiovisuais e cinematográficas quanto aos direitos humanos e fundamentais no período pósguerra e às temáticas relativas à ética, à cultura e à educação. $\mathrm{O}$ presente trabalho busca destacar a relevância do cinema e do audiovisual como instrumentos de difusão de valores auxiliares na edificação de uma sociedade consciente.

Para tanto, em um primeiro momento, partiremos de uma análise da Declaração Universal dos Direitos Humanos, destacando a comunicação e a mídia como um direito humano, tendo entre os seus pilares, a liberdade de expressão. A pesquisa, visando os pressupostos supramencionados, trará um enfoque analítico na indústria cinematográfica mundial, nos movimentos do cinema, na TV aberta brasileira e nas plataformas contemporâneas de exibição.

Isto posto, abordaremos brevemente a origem do cinema, sua trajetória, seus movimentos, alguns de seus diretores e algumas de suas principais produções. A partir do apontamento de algumas obras e suas características, poderemos trabalhar de forma analítica a contribuição ou não do audiovisual para a aplicabilidade dos direitos humanos e fundamentais.

Partindo da análise da teoria crítica de Adorno e Horkheimer, identificaremos como o cinema e o audiovisual, ao longo de boa parte de sua trajetória, foi um auxiliar instrumento de alienação social, com uso de estereótipos, encobrimento da alteridade e elementos padronizados. Por outro lado, veremos como os movimentos e manifestações audiovisuais, com propostas de ruptura, trouxeram uma nova era ao mundo do cinema.

Os movimentos do cinema advindos no período do pós-Segunda Guerra Mundial, em vários países, inauguram um ponto de convergência: a ruptura com o industrialismo cultural. Nesta seara, a observação de novas formas de fazer cinema à luz de ressignificações narrativas será fundamental para a compreensão da relevância destas novas propostas ao universo cinematográfico mundial. Com enfoque no Neorrealismo Italiano, na Nouvelle 
Vague francesa e no Cinema Novo brasileiro, estudaremos as principais características e contribuições de tais processos para a cristalização de novos fundamentos éticos presentes neste novo universo criativo, que por vezes é político.

A análise de narrativas contemporâneas insertas em um universo multicultural é de extrema relevância para o entendimento da aplicabilidade de temáticas humanistas no audiovisual. Neste sentido, a série Anne with an E é uma alternativa comprometida com a abordagem responsável de problemáticas relativas às violações dos direitos fundamentais. Ademais, consegue demonstrar que através de ideais de igualdade e do respeito à alteridade é possível construir uma sociedade justa, fraterna e plural.

$\mathrm{Na}$ perspectiva brasileira, é válido ressaltar que a Constituição Federal de 1988 estabelece que os veículos de comunicação devem atender pressupostos éticos de fomento à cultura e à educação. Desta forma, as emissoras de rádio e televisão têm como compromisso a exibição de conteúdos que atendam tais requisitos.

Diante disso, temos a obra do diretor brasileiro Luiz Fernando Carvalho, a qual cumpre os pressupostos constitucionais por meio da apresentação e valorização da cultura brasileira em narrativas com forte apelo poético e estético que resgatam elementos presentes em manifestações artísticas de diversas regiões que constituem o patrimônio nacional.

Portanto, reúnem-se neste texto diversas obras, movimentos e narrativas, as quais, compreendidas como instrumentos sociais, buscam estabelecer a importância do cinema e do audiovisual em meio a temáticas que valorizem a pluralidade, o fomento à cultura, à educação e o respeito aos direitos humanos e fundamentais.

\section{DIREITOS HUMANOS E A SUA APLICABILIDADE NAS MÍDIAS CONTEMPORÂNEAS}

Os direitos humanos e fundamentais consagraram-se para a humanidade após grandes atrocidades cometidas durante o período da Segunda Guerra Mundial. Fazia-se necessário resgatar ou até mesmo (re) afirmar que todos os indivíduos, apesar das inúmeras diferenças biológicas e culturais, são dignos de igualdade e respeito. Os seres humanos são os únicos entes no mundo capazes de amar, descobrir a verdade e criar a beleza. Nesse sentido, fez-se preciso reconhecer, de forma universal, que por força dessa radical igualdade nenhum indivíduo, gênero, etnia, classe social, grupo religioso ou nação pode afirmar-se superior aos demais (COMPARATO, 2003). 
A Declaração Universal dos Direitos Humanos, aprovada em 1948 pela Assembleia Geral das Nações Unidas, traz em seu bojo a internacionalização dos direitos humanos, isto é, sua intervenção na elaboração de tratados, convenções e constituições, buscando efetivar os direitos humanos e fundamentais em todo mundo. A proteção dos direitos fundamentais necessitou ser assegurada através de um regime de direito, para que nenhum indivíduo seja submetido novamente a nenhuma forma de tirania e opressão.

Tal documento dispõe em seu Artigo 19 que "todo o indivíduo tem direito à liberdade de opinião e de expressão, o que implica o direito de não ser inquietado pelas suas opiniões e o de procurar, receber e difundir, sem consideração de fronteiras, informações e ideias por qualquer meio de expressão" (DECLARAÇÃO UNIVERSAL DOS DIREITOS HUMANOS, 1948, Art. 19). Ou seja, a comunicação, em todas as suas formas, é afirmada em tal documento como um direito humano a ser reivindicado, com interferência direta na garantia ou negação dos demais direitos (MELO; DANTAS; BRITO, 2013). Logo, a mídia, os meios de comunicação e as produções audiovisuais devem cumprir uma responsabilidade social, já que possuem o livre exercício de suas funções respaldados por um arcabouço legislativo e também por serem considerados espaços políticos com capacidade de construir valores, propagar ideias e influenciar comportamentos (MELO; DANTAS; BRITO, 2013).

Entretanto, é notório que em determinadas situações a mídia pode desempenhar um papel dicotômico, já que tanto pode atuar como instrumento de construção de uma cultura de respeito aos direitos humanos quanto, por outro lado, pode reproduzir e legitimar violações a esses direitos, fortalecendo no imaginário social o preconceito e a opressão (MELO; DANTAS; BRITO, 2013).

Neste artigo, abordaremos a aplicabilidade dos direitos humanos e fundamentais nas produções audiovisuais no Brasil e no mundo, analisando de forma específica a ocorrência da promoção ou violação desses direitos, com enfoque na indústria cinematográfica mundial, nos movimentos do cinema, na TV aberta brasileira e nas plataformas contemporâneas de exibição.

\section{OS DIREITOS HUMANOS E AS PRODUÇÕES AUDIOVISUAIS}

Neste ponto, após percorrermos uma travessia pela história do cinema, apontaremos como o cinema e o audiovisual comportaram-se frente aos direitos humanos fundamentais e às barbáries do período pós-guerra. Por intermédio dos movimentos cinematográficos do 
Brasil e do mundo, abordaremos o papel do cinema como instrumento artístico de resistência ao autoritarismo, à tirania e à opressão.

\subsection{Um breve histórico do cinema}

O cinema, como uma das principais manifestações audiovisuais, teve seu início marcado pela trajetória dos irmãos Lumière, na França, por volta de 1895. Auguste e Louis Lumière inventaram o cinematógrafo, um aparelho que trazia consigo a câmera de filmagem e o projetor de imagens, possibilitando a ocorrência da considerada primeira sessão comercial de cinema, no ano de 1895, em Paris (COSTA, 1995). Um dos primeiros longas metragens a ser exibido na história do cinema, com o formato de sequência (blocos de ação), foi Viagem à Lua do cineasta francês George Méliès. Tal produção trazia consigo uma narrativa crítica aos valores vitorianos e aos efeitos da Revolução Industrial na Europa Ocidental (LEIGHT, 2016).

Na década de 1920, o expressionismo alemão ganha destaque com o estilo antirrealista, herdado do movimento da arte expressionista do início do séc. XX e com o uso da luz como forma de persuasão da plateia. A Era do Preto e Branco, na década de 1930, trouxe às telas grandes clássicos, como a sensível comédia Luzes da Cidade e Tempos Modernos, com alto teor crítico das condições trabalhistas no período da Grande Depressão, ambos de Charles Chaplin. Outras produções pioneiras despontaram nesse contexto, como Metropolis, do diretor Fritz Lang, sendo a primeira distopia a ser exibida em uma sociedade alemã segregada (LEIGHT, 2016).

O cinema narrativo clássico ganha destaque na década de 1940 , no período denominado "Era de Ouro de Hollywood" (LEIGHT, 2016), com sucessos de bilheteria como ... E o vento levou de Victor Fleming e o grande expoente da indústria hollywoodiana Cidadão Kane de Orson Welles. Na mesma década, emerge o movimento do Neorrealismo Italiano, caracterizado por abordar narrativas sobre a classe trabalhadora e problemas sócioeconômicos da Itália pós-Segunda Guerra. Tal estilo buscou sempre retratar, mesmo em produções com poucos recursos financeiros, o desespero, a opressão e desigualdade social enfrentadas pelo país.

Grandes longas despontaram na década de 1950, período marcado pelo temor da Guerra Fria e por temas como vida e morte, sendo esta a marca registrada do cineasta Ingmar Bergman em filmes como O Sétimo Selo e Morangos Silvestres. o suspense ganha destaque no final da década com as produções do cineasta Alfred Hitchcock (LEIGHT, 2016). 
No início dos anos 60, movimentos de vanguarda do cinema e de ruptura com narrativas clássicas e comerciais começam a surgir. A Nouvelle Vague ou "nova onda" desponta na França com o longa Acossado do cineasta Jean-Luc Godard, dando uma nova vida ao cinema (LEIGHT, 2016). Paralelamente, no Brasil, nasce o movimento Cinema Novo, com forte apelo intelectual, político e com críticas sociais ácidas, apresentando-se, logo, como uma resposta ao cinema tradicional (KREUTZ, 2018a).

A partir dos anos 70, produções características da denominada "Nova Hollywood" começam a irromper. Filmes como o "blockbuster" O Poderoso Chefão do diretor Francis Ford Coppola, Taxi Driver de Martin Scorsese, Paris, Texas de Wim Wenders, O Sacrifício de Andrei Tarkovsky e Tudo Sobre Minha Mãe de Pedro Almodóvar são grandes representantes deste período (LEIGHT, 2016).

\title{
3.2 O cinema e o audiovisual à luz da teoria crítica de Adorno e Horkheimer
}

Durante boa parte da primeira metade do século XX, o cinema esteve inserto em um contexto intimamente ligado ao que os autores Theodor Adorno e Max Horkheimer entendiam por Indústria Cultural.

\begin{abstract}
Filmes, rádio e semanários constituem um sistema. Cada setor se harmoniza em si e todos entre si. As manifestações estéticas, mesmo a dos antagonistas políticos, celebram da mesma forma o elogio do ritmo do aço. [...] Filme e rádio se autodefinem como indústrias, e as cifras publicadas dos rendimentos de seus diretores-gerais tiram qualquer dúvida sobre a necessidade social de seus produtos (HORKHEIMER; ADORNO, 2002, p. 169-170).
\end{abstract}

Para os autores frankfurtianos, a Indústria Cultural compreende a fragmentação e a diferenciação como potenciais instrumentos de manutenção de aparências, tendo em vista que a sociedade capitalista possui como um dos seus pressupostos principais a padronização essencial e estrutural, a qual, em seu cerne é resultante de articulações internas do próprio modo de produção (COELHO, 2002).

Distinções enfáticas, como entre filmes de classe A e B, ou entre histórias em revistas a preços diversificados, não são tão fundadas na realidade, quanto, antes, servem para classificar e organizar os consumidores a fim de padronizá-los. Para todos, alguma coisa é prevista a fim de que nenhum possa escapar; as diferenças vêm cunhadas e difundidas artificialmente. O fato de oferecer ao público uma hierarquia de qualidades em série serve somente à quantificação mais completa (HORKHEIMER; ADORNO, 2002, p. 172) 
O cinema como indústria teve seu principal modelo de organização em Hollywood, mais propriamente em meados do século XX. Para Adorno e Horkheimer, o novo modelo industrial privou o homem moderno da concepção de crítica e pensamento, tendo em consideração que as produções cinematográficas eram repletas de estereótipos e superficialidades impostas por narrativas padronizadas que, em nome do lazer, atrofiavam a capacidade analítica do espectador e promoviam o encobrimento da alteridade.

Nesse sentido, a denominada "Era de Ouro de Hollywood", situada no contexto do cinema narrativo clássico, é um exemplo, dentro da trajetória cinematográfica, da apropriação do audiovisual para o fortalecimento do arcabouço das prerrogativas da indústria cultural (CAROLLI; VARÃO, 2009).

\section{OS MOVIMENTOS DO CINEMA PÓS-SEGUNDA GUERRA E OS DIREITOS HUMANOS}

Em contrapartida ao cinema comercial e alienante inserto na indústria cultural, a partir da década de 1940, no contexto histórico do pós-segunda guerra, o surgimento de movimentos cinematográficos de vanguarda com narrativas revolucionárias começou a ocorrer. Dentre estes movimentos, podemos destacar como exemplos: o Neorrealismo Italiano, a Nouvelle Vague na França, o Cinema Novo no Brasil, o Cinema Livre na Inglaterra, a Escola de Cinema Polonesa e o Cinema Paralelo Indiano. Neste estudo, para fins de compreensão, abordaremos de forma específica o Neorrealismo italiano, a Nouvelle Vague francesa e o Cinema Novo brasileiro, analisando suas propostas de narrativa em convergência com os direitos humanos e fundamentais.

\subsection{O neorrealismo italiano e as temáticas do pós-segunda guerra}

O segundo parágrafo do Preâmbulo da Declaração Universal dos Direitos Humanos (1948) ressalta que o desprezo e o desrespeito aos direitos humanos resultaram em atos bárbaros que ultrajaram a consciência da Humanidade. Portanto, fazia-se necessário vislumbrar o advento de um mundo no qual todos pudessem gozar de liberdade de palavra, de crença e de viverem e assim permanecerem a salvo do temor de novos tempos sombrios. Neste contexto, a arte, em especial o cinema italiano, buscou retratar questões sociais surgidas no pós-guerra em consonância com a consciência humanista surgida na década de 1940.

O Neorrealismo Italiano desponta nos anos 1940, caracterizado, principalmente, por narrativas sobre a classe trabalhadora, com a abordagem de temas relativos às dificuldades 
econômicas e sociais da Itália pós-Segunda Guerra Mundial (1939-1945). Considerado uma das bases do cinema moderno, tal movimento foi desenvolvido por um grupo de críticos da revista Cinema, que incluía: Luchino Visconti, Gianni Puccini, Cesare Zavattini, Giuseppe de Santis e Pietro Ingrao. Estes cineastas propunham uma espécie de reação à guerra e ao que ela representava. As produções caminhavam na contramão de filmes comerciais populares, desconstruindo formatos cinematográficos estabelecidos, com inspiração nos escritores realistas da virada do século XX (KREUTZ, 2018b).

O movimento neorrealista traz um novo marco na cultura italiana. Com a presença de narrativas e ideias contemporâneas, os filmes reagiam às banalidades que predominavam no cinema vigente naquele período. Os longas-metragens também continham uma estética de caráter documental, uso de locações reais, escalação de atores amadores e diálogos improvisados, por meio dos quais os cineastas buscavam escapar de artifícios estilísticos (KREUTZ, 2018b). Tal movimento, através de retratos de classes oprimidas pela tirania e por circunstâncias políticas, inaugura, além de um novo estilo cinematográfico, uma filosofia ética e moral que buscou libertar o cinema das superficialidades hollywoodianas e fundar um novo marco cultural em um país devastado pelo passado fascista e pela guerra.

\subsection{A estética revolucionária da nouvelle vague}

A Nouvelle Vague francesa foi um dos principais movimentos do cinema moderno europeu e um dos maiores expoentes da história da sétima arte. O termo "Nouvelle Vague" ou "nova onda" foi utilizado inicialmente entre o final da década de 1950 e início dos anos 1960, na França, por um grupo de críticos cinematográficos da revista Cahiers du Cinèma. Tal movimento artístico teve como base teórica os escritos de Alexandre Astruc e André Bazin e o conceito de caméra-stylo, ou seja, como se o cineasta escrevesse com a luz, usando a câmera como caneta (KREUTZ, 2018c).

A desconstrução das bases do cinema comercial, a utilização da técnica como estilo, a ruptura com lógicas narrativas tradicionais, a concepção do cineasta como autor, a rejeição da estética da montagem, o uso de longos planos e de profundidade (mise-en-scène) e a "escrita com a luz" ou "caméra-stylo" moldaram o surgimento da apoteótica Nouvelle Vague, a qual tinha em François Truffaut e Jean-Luc Godard seus principais expoentes. A estrutura narrativa, desta maneira, deveria ser uma forma de expressão artística pessoal do autor, deixando visível sua assinatura na obra, segundo a "politique des auteurs" (política dos autores) idealizada por Astruc (KREUTZ, 2018c). 
O desejo comum dos autores da "Nova Onda" colocava-os à luz de eventos históricos e políticos que necessitavam de representação. $\mathrm{O}$ uso de locações reais, a abordagem de temas de cunho social, o engajamento dos cineastas, o pano de fundo das revoltas políticas e sociais com temáticas diversas e o uso de narrativas radicalmente experimentais em termos de estilo e edição situavam os diretores na esfera de rupturas e quebra de paradigmas conservadores, tão necessária na mítica década de 1960 (KREUTZ, 2018c). Inspirada pelo neorrealismo italiano, a "Nouvelle Vague" se impôs na utilização do cinema e do audiovisual como instrumento de transformação social, diferenciando-se não apenas pela busca de renovação do mundo através do cinema, mas pela conexão da sétima arte com as inquietações contemporâneas insurgentes no período do pós-Segunda Guerra.

O movimento apresentou uma estética inédita, com longos planos sequência, improvisação de diálogos, ausência de continuidade, ironia, sarcasmo e diversas referências a outras obras cinematográficas, trazendo um frescor visual ao cinema. Apoiado majoritariamente pelo público jovem, a "Nova Onda" vanguardista propõe uma verdadeira rebelião contra os métodos cinematográficos característicos do contexto de Indústria Cultural. Ao contrário do cinema narrativo clássico, a Nouvelle Vague inaugurou novas técnicas de estilo e direção, sem depender de grandes orçamentos e ainda permitiu aos espectadores fatores de identificação com questões existenciais, anseios e modos de vida intrínsecos à juventude francesa (KREUTZ, 2018c).

\subsection{O cinema novo, a estética da fome e os direitos fundamentais}

"Todos os seres humanos nascem livres e iguais em dignidade e direitos. São dotados de razão e consciência e devem agir em relação uns aos outros com espírito de fraternidade" (DECLARAÇÃO DOS DIREITOS HUMANOS, 1948, Art. I). Os direitos fundamentais são garantidos em um arcabouço legislativo internacionalizado de caráter formal e com o ideal de atingir todos os povos e nações. Contudo, as desigualdades herdadas de duros processos históricos por vezes inviabilizaram a aplicação material de tais garantias. Em um contexto histórico-político extremamente conturbado, no qual o conservadorismo e a repressão ganhavam força, o Brasil, artisticamente, pôde contar com uma geração de cineastas que buscavam lutar contra o empobrecimento intelectual, armados com a arte.

"Uma câmera na mão e uma ideia na cabeça", a frase de Glauber Rocha, cineasta baiano que ganhou o mundo, busca sintetizar a lógica e o princípio ativo da nova forma de fazer cinema: a política atrelada à intelectualidade. O Cinema Novo no Brasil, movimento 
artístico de caráter politizado e sintonizado com a dura realidade das camadas populares e trabalhadoras foi considerado, naquele período, o cinema mais político da América Latina. O movimento, bem como outras manifestações artísticas, surgiu como uma resposta ao cinema tradicional hollywoodiano que ganhava as bilheterias nacionais, contando com uma juventude comprometida a mudar e combater o cinema imerso no industrialismo cultural e na alienação. A geração de cineastas buscava, sobretudo, uma arte engajada movida por preocupações sociais e com elementos da cultura brasileira (KREUTZ, 2018a).

A Primeira Fase do Cinema Novo continha o cerne ideológico do movimento, com temáticas sociais que retratavam as desigualdades, a fome, a violência, a alienação religiosa e a exploração econômica. Os filmes, com uma exibição extremamente realista das periferias e do sertão, buscavam se afastar da imagem que o Brasil tinha no exterior e acima de tudo criticar a maneira pacífica com a qual os brasileiros lidavam com essas problemáticas sociais. A Segunda Fase do Cinema Novo se instalou quando João Goulart foi deposto pelos militares. Com a instauração de um regime opressivo, os cineastas haviam falhado na luta pela manutenção da democracia, usando a arte como instrumento político. Neste período, a temática dos filmes passou a representar a angústia e a perplexidade do Brasil frente a um regime autoritário. Já, a Terceira Fase do Cinema Novo buscou inspiração na Tropicália, com uma estética repleta de cores, concretismo e elementos da cultura brasileira. Tal período do movimento propunha uma ruptura com a dita arte "bem-comportada".

Glauber Rocha, um dos principais expoentes do movimento, idealizou a denominada "estética da fome", a qual, por meio de um manifesto publicado em 1965, representaria as problemáticas da miséria e da violência em função de construir um novo projeto cinematográfico, o qual, nas palavras de Rocha no filme $O$ vento do Leste (1970), seria o de um "cinema perigoso, divino e maravilhoso".

\footnotetext{
A fome latina, por isto, não é somente um sintoma alarmante: é o nervo de sua própria sociedade. Aí reside a trágica originalidade do Cinema Novo diante do cinema mundial: nossa originalidade é nossa fome e nossa maior miséria é que esta fome, sendo sentida, não é compreendida. Nós compreendemos esta fome que o europeu e o brasileiro na maioria não entendeu. Para o europeu, é um estranho surrealismo tropical. Para o brasileiro, é uma vergonha nacional (ROCHA, 2013, p. 2-3).
}

A "Estética da Fome", considerado o mais relevante manifesto do cinema brasileiro, logo se tornou uma espécie de estatuto do movimento. O documento discorreu acerca de problemas sociais como a fome, a miséria e a violência presentes no Brasil e na América 
Latina para o mundo, tendo estas problemáticas logo se tornado a condição de existência da nova forma de fazer cinema.

O que fez do Cinema Novo um fenômeno de importância internacional foi justamente seu alto nível de compromisso com a verdade; foi seu próprio miserabilismo, que, antes escrito pela literatura de 30 , foi agora fotografado pelo cinema de 60; e, se antes era escrito como denúncia social, hoje passou a ser discutido como problema político (ROCHA, 2013, p. 2).

Diante disso, o Cinema Novo inaugura uma estética que, embora ausente de recursos e preciosismos técnicos, caracteriza-se por uma liberdade criativa que expressa traços autorais orgânicos dos diretores, e, sobretudo, traz um cinema de resistência que alcançou o mundo e deixou um enorme legado para o audiovisual brasileiro.

\section{ANNE WITH AN E - UMA ALTERNATIVA AUDIOVISUAL CONTEMPORÂNEA DE AFIRMAÇÃO DOS DIREITOS HUMANOS E DISSIPAÇÃO DE PRECONCEITOS}

No cenário contemporâneo, a série canadense Anne with an E, produzida pela $\mathrm{CBC}$ (Canadian Broadcasting Corporation) e distribuída mundialmente através da plataforma de streaming Netflix, configura um importante exemplo de exercício da responsabilidade social da mídia atrelado à difusão dos direitos humanos e fundamentais e à dissipação de preconceitos. A produção audiovisual, baseada na obra literária da escritora canadense Lucy Maud Montgomery, aborda temáticas extremamente relevantes como: sexualidade, papéis de gênero, feminismo e racismo de uma forma acessível e responsável, já que tais assuntos são abordados de forma ética, poética e extremamente educativa.

A série, além de possuir estética, fotografia, roteiro e direção bem trabalhados, cumpre, de forma exemplar, sua responsabilidade social ao retratar problemáticas sociais e violações dos direitos humanos, contando com um arco narrativo comprometido em demonstrar que, mesmo com significativas mudanças que acometeram a humanidade, alguns estigmas discriminatórios insistem em permanecer.

Art II - 1. Todo ser humano tem capacidade para gozar os direitos e as liberdades estabelecidos nesta Declaração, sem distinção de qualquer espécie, seja de raça, cor, sexo, idioma, religião, opinião política ou de outra natureza, origem nacional ou social, riqueza, nascimento, ou qualquer outra condição (DECLARAÇÃO UNIVERSAL DOS DIREITOS HUMANOS, 1948). 
Retomando o disposto na Declaração Universal dos Direitos Humanos (1948), é notório que a produção audiovisual em questão traz consigo construções narrativas que retratam desigualdades históricas e grandes falhas da humanidade. Contudo, apesar de representar tais temáticas, o enredo, com um texto bem construído, acaba por edificar pontes de esperanças e potenciais caminhos de evolução.

A título de exemplo, há núcleos na trama em que se é possível visualizar tais aspectos: o fato de mulheres não terem nenhum tipo de participação nas decisões políticas da cidade, sendo estas tomadas por um grupo de homens anciãos e a censura imposta ao jornal da escola por tratar de temas progressistas demonstram que, apesar destes conflitos serem proeminentes da época de ambientação da série, temáticas como estas e outras são diariamente refletidas em situações contemporâneas.

A produção, além de tudo, conta com uma protagonista afetuosa e idealista que se depara com uma sociedade enraizada em valores patriarcais, práticas racistas, condutas xenófobas e princípios arcaicos, marcada pelo preconceito e pela discriminação. Nesse cenário, a personagem principal busca encarar as adversidades e propor soluções à luz do humanismo e de práticas de igualdade (PASSOS, 2020). Destarte, é perceptível que os temas e as problemáticas sociais trabalhadas, apesar de serem atinentes ao fim do século XIX, ainda se refletem na sociedade pós-moderna.

\section{A COMUNICAÇÃO E O AUDIOVISUAL NO BRASIL: AS PREVISÕES CONSTITUCIONAIS}

É sabido que a Constituição Federal de 1988 deu grande valor à cultura, tornando- a fator determinante para a formação educacional do povo. Encontram-se introduzidos neste arcabouço elementos constituintes da identidade, da ação, dos costumes e da memória dos diversos grupos formadores da sociedade brasileira. O Estado, desta forma, é caracterizado como o agente responsável pela garantia do pleno exercício dos direitos culturais e do acesso às fontes de cultura nacional, apoiando e incentivando a valorização e a difusão das manifestações culturais populares, indígenas, afro-brasileiras e a de outros grupos participantes da construção da identidade brasileira (SILVA, 2005).

De acordo com o Artigo 215 da Constituição Federal (1988):

Art. 215. O Estado garantirá a todos o pleno exercício dos direitos culturais e acesso às fontes da cultura nacional, e apoiará e incentivará a valorização e a difusão das manifestações culturais. 
$\S 1^{\circ} \mathrm{O}$ Estado protegerá as manifestações das culturas populares, indígenas e afrobrasileiras, e das de outros grupos participantes do processo civilizatório nacional. $\S 2^{\circ}$ A lei disporá sobre a fixação de datas comemorativas de alta significação para os diferentes segmentos étnicos nacionais.

$\S 3^{\circ}$ A lei estabelecerá o Plano Nacional de Cultura, de duração plurianual, visando ao desenvolvimento cultural do País e à integração das ações do poder público que conduzem à:

I - defesa e valorização do patrimônio cultural brasileiro;

II - produção, promoção e difusão de bens culturais;

III - formação de pessoal qualificado para a gestão da cultura em suas múltiplas dimensões;

IV- democratização do acesso aos bens de cultura;

V - valorização da diversidade étnica e regional (BRASIL, 1988).

Neste sentido, os meios de comunicação, especialmente o audiovisual, podem ser compreendidos como um dos principais instrumentos de difusão da cultura, atrelada a valores éticos e educativos. Vale ressaltar que tais veículos de comunicação são concessões públicas, ou seja, cabe à União explorar diretamente ou mediante autorização, concessão ou permissão, os serviços de rádio e TV, conforme estabelece o Art. 21, XII, alínea a da Constituição Brasileira. Além disso, o Art. 221 da Carta Magna de 1988 estabelece que:

\footnotetext{
Art. 221. A produção e a programação das emissoras de rádio e televisão atenderão aos seguintes princípios:

I - preferência a finalidades educativas, artísticas, culturais e informativas;

II - promoção da cultura nacional e regional e estímulo à produção independente que objetive sua divulgação;

III - regionalização da produção cultural, artística e jornalística, conforme percentuais estabelecidos em lei;

IV - respeito aos valores éticos e sociais da pessoa e da família. (BRASIL, 1988)
}

Portanto, haja vista que o rádio e a televisão brasileira configuram relevantes veículos de comunicação, os quais, além de serem concessões públicas, ainda estão presentes no cotidiano de boa parte da população brasileira - dados do IBGE (2018) apontam que 96,4\% dos domicílios no país possuem televisão -, é notória a necessidade destes meios de comunicação assumirem uma responsabilidade social com relação aos conteúdos exibidos, buscando promover a cultura, a ética e a educação por meio das suas programações.

\section{A ÉTICA E A ESTÉTICA DE LUIZ FERNANDO CARVALHO COMO PRESSUPOSTO CRIATIVO}

Luiz Fernando Carvalho é um cineasta, roteirista e diretor de televisão brasileiro. Sua obra, além de atravessar de forma imersiva diversas manifestações artísticas, possui uma 
estética repleta de elementos da cultura popular e tem um forte elo com a literatura brasileira. A travessia de Carvalho propõe rupturas que, através da linguagem e da busca por elementos da identidade cultural de um Brasil profundo, cumpre, efetivamente, a responsabilidade social do audiovisual exibido em grandes veículos de comunicação de promover a ética, a educação e a cultura (BIO, 2018).

\begin{abstract}
Acredito que a TV tenha que cumprir a missão da pluralidade de narrativas e temas. Quero dizer que o modo de se contar um acontecimento é muitas vezes mais importante que o próprio acontecimento. A isto quero chamar de linguagem. [...] Quanto mais plural tudo for, melhor para cultura e para o país, e a TV, assim como cinema e literatura e todos os órgãos públicos e concessões públicas que compõem a tal "indústria cultural", têm que compartilhar conhecimento com o público, com o homem mais simples, humilde, que não tem condições de viajar o mundo e conhecer outras culturas. Somos um país que, de forma muito generosa, abraçou e segue abraçando todas essas diásporas que, já nos dias de hoje, contribuem para a formação do povo brasileiro, então temos que oferecer um conteúdo estético que contenha todas essas camadas culturais. (CARVALHO, 2018, [online])
\end{abstract}

A partir de narrativas que exploram as potencialidades e pluralidades da cultura brasileira, os trabalhos realizados por Luiz Fernando Carvalho na TV são marcados por uma linguagem poética e uma estética intrinsecamente experimental. Tais recursos são resultados de um processo criativo que visa, a partir da colaboração de diversas manifestações artísticas, edificar produções que valorizem elementos da cultura popular, da literatura e da memória nacional. Desta forma, não apenas realizam, de forma viva e dialógica, a função ética dos meios de comunicação, como levam aos lares de milhões de brasileiros conteúdos instrumentos de educação, os quais auxiliam significativamente no resgate da identidade do Brasil e na formação de cidadãos.

Diante da análise das obras dirigidas por Luiz Fernando Carvalho, será possível visualizar o resgate de narrativas, elementos, rituais e manifestações artísticas componentes da identidade cultural brasileira. Dessa forma, com o uso de recursos cuidadosamente construídos em um arcabouço poético, Carvalho vai moldando tal como um artista, histórias e narrativas que perpassam universalidades culturais por meio de uma estética artesanal e barroca.

\title{
7.1. Hoje é dia de maria: o resgate de uma identidade cultural
}

A minissérie Hoje é dia de Maria foi produzida e exibida pela Rede Globo, em 2005, com roteiro e direção de Luiz Fernando Carvalho. A narrativa é inspirada em elementos folclóricos e míticos oriundos de contos populares compilados por Câmara Cascudo, Mário de 
Andrade e Sílvio Romero. Indicada ao Emmy Internacional, a produção conta a saga de Maria, uma menina que perde a mãe e passa a conviver com as maldades de sua madrasta e com as bebedeiras de seu pai. Diante de tudo isso, Maria decide fugir de casa. A menina passa a enfrentar diversas dificuldades em sua travessia, inclusive as artimanhas do demônio Asmodeu, o senhor dos descaminhos, em suas múltiplas facetas. Entretanto, Maria não desiste de percorrer o seu caminho em direção às franjas do mar, seu grande sonho (HOJE É DIA DE MARIA, 2018). Na cidade, Maria depara-se com diversos problemas sociais, quais sejam: a violência, o consumismo, a exploração de menores, a opressão feminina, as leis de mercado, a ganância e a guerra, tendo como alento e suporte apenas a proteção de um nobre cavaleiro andante, Dom Chico Chicote, defensor da poesia e da justiça, que lhe ensina: "É pelos sonhos que vamos".

Nas palavras de Carvalho:

Hoje é Dia de Maria traz uma afirmação do inconsciente brasileiro, do subterrâneo brasileiro, com a liberdade de não ser regionalista. Uma tentativa com muita delicadeza porque o fio que está conduzindo isso é o fio da infância, o fio da memória. Mas se tivesse que resumir tudo em uma única palavra, seria ancestralidade. [...] Como em uma colheita, estamos todos trabalhando para devolver ao Brasil o fruto que o próprio povo semeou em meio a sua formação. Os contos populares são essa semente. Aos olhos do mundo globalizado de hoje, sinto que é um trabalho de responsabilidade imensa. Usando um clichê diria, até, de resistência já que não há país que resista abrindo mão de sua memória (HOJE É DIA DE MARIA, 2018, [online]).

A minissérie, além de trazer à tona o sincretismo cultural presente no Brasil, realiza uma busca por elementos artísticos populares, muitas vezes perdidos ou esquecidos no imaginário brasileiro. Desta forma, guiado por uma liberdade criativa de caráter orgânico, Carvalho faz emergir uma obra que, a partir da representação da infância, consolida-se em um verdadeiro retrato do Brasil profundo, genuinamente constituído por seus contos populares, por sua tradição oral e por suas leituras e releituras da própria história e da própria cultura.

\subsection{Capitu: a estética do anacronismo}

Capitu, minissérie brasileira dirigida por Luiz Fernando Carvalho, foi ao ar em 2008 pela Rede Globo. Roteirizada a partir do livro Dom Casmurro de Machado de Assis, a produção é concebida pelo diretor como uma aproximação da obra clássica da literatura brasileira, a qual narra, em primeira pessoa, a história de Bento Santiago, ou Dom Casmurro. Tal narrador, que desperta a desconfiança do leitor a partir de uma redação unilateral, escreve 
um livro com o objetivo de restaurar suas memórias e seus momentos vividos ao lado de Capitu, seu grande amor.

Aqui, o diretor afirma:

\begin{abstract}
Na minissérie, estou reafirmando a dúvida presente em Dom Casmurro como parte do processo cultural e dialético da modernidade. E acredito que a dúvida não é amoral ou imoral, não é um pecado. O escritor do romance, Machado de Assis surge como um avanço em seu tempo, uma nova proposta estética em relação à literatura da época que se produzia no país e no mundo. A opção pelo caminho da dúvida eleva o romance ao mítico embate entre a mera aparência das coisas e a verdade do mundo (CAPITU, 2018, [online]).
\end{abstract}

A minissérie, fazendo uso de uma estética anacrônica, traz uma abordagem baseada na memória, por vezes caricaturada do protagonista. Com o uso de elementos teatrais, figurinos do século XIX e recursos que sustentam a atemporalidade da narrativa, Carvalho constrói uma ópera-rock que demonstra, nas palavras do diretor, "a dúvida presente em Dom Casmurro como parte do processo cultural e dialético da modernidade" (CAPITU, 2008, [online]). Desta forma, desfrutando da literatura como fonte, a minissérie responsável por transfigurar um grande clássico da literatura brasileira traz possibilidades de sincretismo cultural e ressignificações de temporalidade.

\title{
7.3. Velho chico: o sertão mágico
}

A telenovela Velho Chico, com direção de arte e direção geral de Luiz Fernando Carvalho, foi ao ar em 2016 pela Rede Globo. A trama é ambientada às margens do Rio São Francisco, na cidade fictícia de Grotas - BA e narra a história de amor proibido, marcada por conflitos entre duas famílias. Com forte crítica social, a telenovela revela facetas de um sertão ainda marcado pelas amarras do coronelismo (VELHO CHICO, 2018).

Com uma estética que reflete a brasilidade, Velho Chico é um retrato realista de um país que tem na figura do homem sertanejo a sua verdadeira face. A fotografia em tons terrosos, figurinos que remetem à tropicália e cenários representativos do barroco e do sincretismo religioso auxiliam a edificar um sertão mágico e poético, que supera as representações de seca e aridez que insistem em permear a cena do audiovisual.

As raízes de um Brasil, a fecundidade estética de uma terra árida, a riqueza cultural apresentada através de elementos humanos e artísticos, e personagens que trazem conseguem ideais de mudança e sustentabilidade, representam um alento ético, que através da estética 
leva às televisões de milhões de cidadãos uma produção a qual se edifica como obra de arte e quebra paradigmas dentro de uma teledramaturgia machucada por clichês, vícios e maniqueísmos.

\section{CONSIDERAÇÕES FINAIS}

É sabido que os direitos humanos e fundamentais, ao se consolidarem por meio de estrutura normativa, vincularam normas de respeito à dignidade humana e respeito às diferenças para a humanidade. Nesse sentido, de que forma manifestações artísticas como o cinema e o audiovisual contribuíram, como instrumentos éticos, para a difusão destes valores?

A trajetória do cinema e do audiovisual na história revela-se um arcabouço de múltiplas narrativas, abordagens, estéticas e características técnicas. Tal travessia, contudo, evidencia que a sétima arte por vezes auxiliou na disseminação de ideais insertos em um contexto de industrialismo cultural, com vistas a ser uma ferramenta de alienação repleta de narrativas superficiais e estereótipos, refletores da negação da alteridade e do encobrimento do outro.

Desta forma, ao longo da primeira metade do séc. XX, as produções audiovisuais e cinematográficas caracterizaram-se por traçarem um alinhamento com tramas padronizadas, firmadas em lugares-comuns. Logo, era necessária a construção de histórias comprometidas a percorrerem um novo rumo, com a presença de narrativas, estéticas e questionamentos que espelhassem atributos próprios ao nascimento de um novo marco cultural.

Assim, movimentos aflorados no período pós-segunda guerra passaram a expressar uma nova forma de fazer cinema. O mundo, da Nouvelle Vague ao Cinema Novo, de Godard a Glauber Rocha, passou a vislumbrar que os direitos humanos, as temáticas emergentes após o passado nazi fascista dos países assolados pela guerra, a fome, o miserabilismo e as reivindicações políticas necessitavam de um lugar nas grandes telas.

As novas ondas passaram a tomar conta dos cinemas no mundo e a construir arcos narrativos e estéticos que serviram de legado para o audiovisual contemporâneo. Atualmente, diversas produções visam a representação das pluralidades, como por exemplo, a série Anne with an $E$, reforçando, logo, o compromisso com a construção de sociedade que tenha a justiça e a igualdade como temas prioritários.

Para além dos movimentos cinematográficos trabalhados, no Brasil, há também produções exibidas na TV, as quais, em consonância com as disposições constitucionais 
acerca da comunicação e do audiovisual, expressam a importância da ética para a construção narrativa. Logo, a obra de Luiz Fernando Carvalho revela ser o expoente da reunião de tais pressupostos, trazendo para a dramaturgia a valorização do vasto celeiro cultural do país.

Dessa forma, sendo o cinema e o audiovisual instrumentos narrativos que percorrem pluralidades e ressignificações de linguagem é necessário, remetendo às palavras de Glauber Rocha (2013), que estes não deixem sua criatividade estética desaparecer em nome de uma objetividade comercial ou de um imediatismo político.

\section{REFERÊNCIAS}

BIO. Luiz Fernando Carvalho, 2018. Disponível em: http://luizfernandocarvalho.com/bio/. Acesso em: 1 de jun. de 2020.

BRASIL. Constituição da República Federativa do Brasil. Brasília: Senado Federal, 1988. Disponível em: http://www.planalto.gov.br/ccivil_03/constituicao/constituicao.htm. Acesso em: 1 de jun. de 2020.

CAROLLI, Bruna; VARÃO, Rafiza. Arte e indústria cultural: uma análise dos diferentes papéis do Cinema. In: CONGRESSO BRASILEIRO DE CIÊNCIAS DA COMUNICAÇÃO, 32., 2009, Curitiba. Anais Eletrônicos... São Paulo: Intercom, 2009. p. 1-12. Disponível em: http://www.intercom.org.br/papers/nacionais/2009/resumos/R4-2353-1.pdf. Acesso em: 2 de jun. de 2020.

CARVALHO, Luiz Fernando. Luiz Fernando Carvalho dá tempo na TV e reflete: "A repetição maniqueísta dos atores tira a credibilidade das histórias". [Entrevista concedida a] Júlia Moura. Glamourama. [online]. Disponível em: https://glamurama.uol.com.br/luizfernando-carvalho-da-tempo-na-tv-e-reflete-a-repeticao-maniqueista-dos-interpretes-paratodo-o-conteudo-tira-a-credibilidade/. Acesso em: 2 de jun. de 2020.

CAPITU. Luiz Fernando Carvalho, 2018. Disponível em: http://luizfernandocarvalho.com/projeto/capitu/. Acesso em: 3 de jun. de 2020.

COELHO, Cláudio Novaes Pinto. O Conceito de Industria Cultural e a Comunicação na Sociedade Contemporânea. Communicare. [online]. 2002, v. 2, n. 2, p. 35-46. Disponível em: https://casperlibero.edu.br/wp-content/uploads/2014/07/O-conceito-de-industria-culturale-a-comunica\%C3\%A7\%C3\%A3o-na-sociedade-contempor\%C3\%A2nea.pdf. Acesso em: 1 de jun. de 2020.

COMPARATO, Fábio Konder. Afirmação Histórica dos Direitos Humanos. 3. ed. São Paulo: Editora Saraiva, 2003.

COSTA, Flávia Cesarino. O primeiro cinema. São Paulo: Scritta, 1995.

DECLARAÇÃO UNIVERSAL DOS DIREITOS HUMANOS. 1948. Disponível em: https://nacoesunidas.org/wp-content/uploads/2018/10/DUDH.pdf. 
HOJE É DIA DE MARIA. Luiz Fernando Carvalho, 2018. Disponível em:

http://luizfernandocarvalho.com/projeto/hoje-e-dia-de-maria/. Acesso em: 3 de jun. de 2020. HORKHEIMER, Max; ADORNO, Theodor. A indústria cultural: o iluminismo como mistificação de massas. Tradução de Júlia Elisabeth Levy. In: LIMA, Luiz Costa. Teoria da cultura de massa. 6. ed. São Paulo: Paz e Terra, 2002, p. 169-214.

IBGE - INSTITUO BRASILEIRO DE GEOGRAFIA E ESTATÍSTICA, 2018. Pesquisa Nacional por Amostra de Domicílios Contínua 2018. Rio de Janeiro: IBGE, 2018.

KREUTZ, Katia. Cinema Novo. Academia Inernacional de Cinema, 2018a. Disponível em: https://www.aicinema.com.br/cinema-novo/. Acesso em: 1 de jun. de 2020.

KREUTZ, Katia. Neorrealismo Italiano. Academia Inernacional de Cinema, 2018b. Disponível em: https://www.aicinema.com.br/neorrealismo-

italiano/\#: :text=O\%20Neorrealismo\%20italiano\%20foi\%20um,Mundial\%20(1939\%20a\%20 1945)>. Acesso em: 1 de jun. de 2020.

KREUTZ, Katia. Nouvelle Vague. Academia Inernacional de Cinema, 2018c. Disponível em: https://www.aicinema.com.br/nouvelle-vague/. Acesso em: 1 de jun. de 2020.

LEIGHT, Danny (org.). O Livro do Cinema. São Paulo: Globo Livros, 2016.

MELO, P. V.; DANTAS, R.; BRITO, T.. Mídia e Direitos Humanos: um debate necessário. Carta Capital, São Paulo, 9 de dez. de 2013. Disponível em:

https://www.cartacapital.com.br/blogs/intervozes/midia-e-direitos-humanos-um-debatenecessario-9408/. Acesso em: 02 de jun. de 2020.

PASSOS, Bruno. Anne with an E (2017-2019): um século à frente. Cinema com Rapadura. 2020. Disponível em: https://cinemacomrapadura.com.br/criticas/572460/critica-anne-withan-e-cbc-2017-2019-um-seculo-a-frente/. Acesso em: 1 de jun. de 2020.

ROCHA, Glauber. Eztetyka da Fome. Hambre - espacio cine experimental. 2013.

Disponível em: https://hambrecine.com/2013/09/15/eztetyka-da-fome/. Acesso em: 2 de jun. de 2020.

SILVA, José Afonso da. Curso de Direito Constitucional Positivo. 25. ed. São Paulo: Malheiros. 2005.

VELHO CHICO. Luiz Fernando Carvalho, 2018. Disponível em: http://luizfernandocarvalho.com/projeto/velho-chico/. Acesso em: 3 de jun. de 2020. 